\title{
Inequality Aversion, Efficiency, and Maximin Preferences in Simple Distribution Experiments: Comment
}

\author{
By Ernst Fehr, Michael Naef, and Klaus M. Schmidt*
}

A major puzzle in the literature on social preferences is that a large majority of subjects behaves as if completely self-interested in some circumstances, such as in competitive experimental markets with standardized goods or in the final rounds of public goods experiments; while in other circumstances a large majority behaves as if strongly motivated by fairness concerns, e.g., in competitive markets with incomplete contracts or in public goods experiments with punishment opportunities. Recently developed models of inequity aversion (Fehr and Schmidt, 1999; Gary E Bolton and Axel Ockenfels, 2000) can explain this puzzle by assuming a heterogeneous population of selfish and inequity-averse subjects. Dirk Engelmann and Martin Strobel (2004, henceforth E\&S) question the relevance of inequity aversion in simple dictator game experiments, claiming that a combination of a preference for efficiency ${ }^{1}$ and a Rawlsian motive for helping the least

\footnotetext{
* Fehr: Institute for Empirical Research in Economics, University of Zurich, Bluemlisalpstrasse 10, CH-8006 Zurich, Switzerland (e-mail: efehr@iew.unizh.ch); Naef: Institute for Empirical Research in Economics, University of Zurich, Bluemlisalpstrasse 10, CH-8006 Zurich, Switzerland (e-mail: naef@iew.unizh.ch); Schmidt: Department of Economics, University of Munich, Ludwigstrasse 28, D-80539 Muenchen, Germany (e-mail: klaus.schmidt@Lrz.uni-muenchen.de). A previous version of this paper was circulated under the title "The Role of Equality, Efficiency, and Rawlsian Motives in Social Preferences." We would like to thank Susanne Kremhelmer for excellent research assistance and Mathias Erlei for very helpful comments on an earlier version of this paper. This paper is part of the research priority program at the University of Zurich on the "Foundations of Human Social Behavior: Altruism and Egoism." Part of this research was conducted while the third author visited Yale University; he would like to thank the Economics Department for its great hospitality. Financial support by the EU-Research Network ENABLE (MRTMCT-2003-505223) is gratefully acknowledged. Schmidt also gratefully acknowledges financial support by the German Science Foundation through SFB-TR 15.

1 "Efficiency" in Engelmann and Strobel (2004) is not defined as Pareto efficiency but as surplus maximization.
}

well-off is more important than inequity aversion.

In this paper, we show that E\&S overstate the relevance of efficiency motives and understate the relevance of inequity aversion. The participants of the E\&S experiments were undergraduate students of economics and business administration. These subjects self-selected into their field of study (economics) and learned in the first semester that efficiency is desirable. Noneconomists, however, may value efficiency much less than economists do. We replicated the most relevant E\&S experiments with various subject pools and are able to show that the dominance of the efficiency motive over the equity motive is restricted to students of economics and business administration. Students from various other disciplines and a sample of nonacademic employees value equality much more highly than efficiency.

This raises the question whether there are other subject characteristics such as gender or political attitudes that affect the preferences for efficiency versus equality. We find a nonnegligible gender effect, indicating that women are more egalitarian than men. Perhaps surprisingly, however, the dominance of equality over efficiency is unrelated to political attitudes, i.e., subjects who vote for right-wing parties and favor right-wing political attitudes are as likely to favor equality as are subjects with left-wing attitudes.

\section{Economists versus Noneconomists}

The most interesting results of E\&S concern their treatments Ey and $\mathrm{P}$ that are designed to discriminate between preferences for efficiency, the Rawlsian maximin motive, and inequity aversion (see Table 1 below). In both treatments, person 2 is the decision maker (dictator) who can choose between allocations A, B, and C. Note that own choices never affect person 2's payoff. Person 2 can redistribute income from a richer person 1 to a poorer person 3 in 
Table 1-Subject Pool Effects: Economists versus Noneconomists

\begin{tabular}{|c|c|c|c|c|c|c|}
\hline \multirow[b]{2}{*}{ Allocation } & \multicolumn{3}{|c|}{ Treatment Ey } & \multicolumn{3}{|c|}{ Treatment $\mathrm{P}$} \\
\hline & A & $\mathrm{B}$ & $\mathrm{C}$ & A & $\mathrm{B}$ & $\mathrm{C}$ \\
\hline Person 1 payoff & 21 & 17 & 13 & 14 & 11 & 8 \\
\hline Person 2 payoff & 9 & 9 & 9 & 4 & 4 & 4 \\
\hline Person 3 payoff & 3 & 4 & 5 & 5 & 6 & 7 \\
\hline Total payoff & 33 & 30 & 27 & 23 & 21 & 19 \\
\hline Average payoff of 1 and 3 & 12 & 10.5 & 9 & 9.5 & 8.5 & 7.5 \\
\hline Efficiency prediction & $\mathrm{A}$ & & & A & & \\
\hline Inequity aversion prediction & & & $\mathrm{C}$ & & & $\mathrm{C}$ \\
\hline Rawlsian maximin prediction & & & $\mathrm{C}$ & A & or $\mathrm{B}$ & or $\mathrm{C}$ \\
\hline \multicolumn{7}{|l|}{ (A) Economists: Berlin (E\&S, 2004) } \\
\hline Choices (absolute) & 12 & 7 & 11 & 18 & 2 & 10 \\
\hline Choices (percent) & 40.0 & 23.3 & 36.7 & 60.0 & 6.7 & 33.3 \\
\hline \multicolumn{7}{|l|}{ (B) Economists: Munich } \\
\hline Choices (absolute) & 72 & 12 & 25 & 63 & 16 & 30 \\
\hline Choices (percent) & 66.1 & 11.0 & 22.9 & 57.8 & 14.7 & 27.5 \\
\hline \multicolumn{7}{|l|}{ (C) Noneconomists: Munich } \\
\hline Choices (absolute) & 22 & 13 & 48 & 21 & 17 & 45 \\
\hline Choices (percent) & 26.5 & 15.7 & 57.8 & 25.3 & 20.5 & 54.2 \\
\hline \multicolumn{7}{|l|}{ (D) Noneconomists: Zurich } \\
\hline Choices (absolute) & & & & 8 & 8 & 20 \\
\hline Choices (percent) & & & & 22.2 & 22.2 & 55.6 \\
\hline \multicolumn{7}{|l|}{ (E) Economists: Zurich } \\
\hline Choices (absolute) & 31 & 9 & 18 & 31 & 9 & 18 \\
\hline Choices (percent) & 53.5 & 15.5 & 31.0 & 53.5 & 15.5 & 31.0 \\
\hline \multicolumn{7}{|l|}{ (F) Noneconomists: Zurich } \\
\hline Choices (absolute) & 61 & 23 & 78 & 53 & 25 & 84 \\
\hline Choices (percent) & 37.7 & 14.2 & 48.1 & 32.7 & 15.4 & 51.9 \\
\hline
\end{tabular}

both treatments by choosing allocations $\mathrm{B}$ or $\mathrm{C}$ instead of allocation A. Choices B and C involve a relatively high efficiency loss, however. In treatment Ey, every additional money unit that is given to the poor person reduces the rich person's income by four money units, while the rich person suffers an income reduction of three units if the poor person's income is increased by one unit in treatment P. In both treatments, a choice of the efficient allocation A constitutes evidence not only against specific functional form assumptions (like piece-wise linearity or positional asymmetry, meaning that subjects prefer advantageous inequity to disadvantageous inequity) in the Fehr-Schmidt approach, but also against general nonlinear versions of inequity aversion. ${ }^{2}$ Treatment $\mathrm{P}$ is particularly important because the decision maker (person 2) always earns the lowest income, independent

\footnotetext{
${ }^{2}$ The inequity aversion approach by Fehr and Schmidt (1999) is compatible with the evidence in several other games conducted by E\&S (the "envy" games) if one allows for nonlinear forms of inequity aversion and gives up the assumption of positional asymmetry.
}

of which allocation is implemented. Thus, the decision cannot be affected by Rawlsian preferences. Therefore, treatment $\mathrm{P}$ constitutes a clean test of the relevance of inequity aversion in comparison to the efficiency motive.

The E\&S evidence for treatment $\mathrm{P}$ also illustrates an important point regarding the interpretation of their results. E\&S conclude that "inequality aversion does not seem to be a major part in a complete explanation" of their data. This conclusion is based on their logit regressions, which neglect any individual heterogeneity. ${ }^{3}$ One-third of their subjects choose the most

\footnotetext{
${ }^{3}$ The conditional logit analysis in E\&S is problematic for two reasons. First, E\&S can estimate the preferences only of an "average subject," which neglects any individual heterogeneity. Second, the independent variables Eff (which captures the sum of the subjects payoff), Self (which captures the decision maker's own payoff), $F S \alpha$ (which captures the disadvantageous inequality), and $F S \beta$ (which captures advantageous inequality) are linearly dependent. Thus, they have to exclude one or more of these variables from the analysis. The decision which variable one should exclude is, however, completely arbitrary, but has strong effects on the regression outcomes. If, as E\&S do, Self is
} 
inefficient and most egalitarian allocation in treatment $\mathrm{P}$, however, suggesting that they are motivated by inequality aversion (see Table 1). Perhaps the most important message that comes from social preferences models is that in strategic interactions the heterogeneity of social preferences is extremely important. As shown in Fehr and Schmidt (1999), even a minority of inequality-averse subjects may have powerful effects on the outcome of strategic interactions. Thus, even if it were true that in general only one-third of the population is motivated by inequality aversion, this motive can have important effects. As we will see below, however, among noneconomists, much more than onethird of the subjects seem to be motivated by inequality aversion.

In a first wave of paid experiment, we examined the subject pool hypothesis by conducting the Ey and P treatments of E\&S with two different subject pools from the University of $\mathrm{Mu}-$ nich. $^{4}$ The first subject pool consisted of 109 first-year undergraduate students in economics and business administration (henceforth called "economists"), while the second subject pool was made up of 83 first- and second-year undergraduates from other disciplines, mostly the social sciences (henceforth called "noneconomists"). Each subject had to make a decision in both of the distribution games discussed above. The results of these experiments are reported in Table 1. For convenience, we also show the results from the E\&S experiments in panel A of this table.

The subject pool effects displayed in Table 1 are striking. The Munich economics and business administration students corroborate the main E\&S result, confirming that preferences for efficiency play a major role among economists (compare panels A and B of Table 1); $66.1 \%$ of the economists opted for the efficient

excluded, $F S \alpha$ and $F S \beta$ are not significant. If, however, $F S \beta$ is excluded, Self and Eff are not significant. Thus, if one takes their regression approach seriously, one could equally well conclude that concerns for efficiency are irrelevant. To make things worse, if one arbitrarily excludes Eff from the analysis, Self and $F S \alpha$ suddenly become highly significant. We owe this argument to Mathias Erlei who respecified and reestimated the $\mathrm{E} \& \mathrm{~S}$ regressions.

${ }^{4}$ In all experiments reported in this paper, subjects made their decisions anonymously, they were paid in private, and there was no role uncertainty, i.e., the decision makers knew that they were in the role of person 2. but most inegalitarian allocation $\mathrm{A}$ in treatment Ey, even exceeding the 40 percent in the E\&S study. The efficiency advantage of allocation A is somewhat lower in game $\mathrm{P}$ and the fraction of economists opting for the efficient allocation A decreases slightly to 57.8 percent, very similar to the E\&S results. The behavior of noneconomists from the University of Munich contrasts sharply with these results, however (see panel C of Table 1). In games Ey and P, the noneconomists chose the inefficient but most egalitarian allocation $\mathrm{C}$ at the rate of 57.8 percent and 54.2 percent, respectively, while only 25 to 27 percent opted for the efficient allocation A. The differences between the noneconomists and the economists from the University of Munich are statistically highly significant $(p<0.001$ in each treatment, Fisher exact test).

An additional paid experiment with noneconomists (college students) in Zurich, Switzerland, who participated only in treatment P, further confirms the robustness of the subject pool effect. A comparison of panels C and D of Table 1 shows that these students' choices were almost identical to those of the noneconomists from the University of Munich $(p>0.93$, Fisher exact test). Only 22 percent choose the efficient allocation A, while 55.6 percent choose the allocation predicted by inequity aversion. The choices of the noneconomists in Munich and $\mathrm{Zu}-$ rich also differ significantly from the choices of the E\&S subjects ( $p<0.001$, Fisher exact test), further supporting a strong subject pool effect.

\section{The Impact of Political Attitudes on Social Preferences}

The strong difference in behavior between economists and noneconomists raises the question of whether there are other subject pool characteristics that might affect the results. Subjects' social preferences could be related to gender, age, or their political attitudes. One might conjecture that more right-wing subjects are less in favor of equality and prefer more efficient allocations than left-wing subjects. If this were the case, or if other subject pool characteristics had a significant impact, we would have to worry about whether our subject pool is representative with respect to these characteristics. To address this concern, we conducted additional experiments where-after subjects had made their choices in treatments Ey and $\mathrm{P}-$ we 
Table 2-Impact of Subject Pool, Political Attitude, and Gender

\begin{tabular}{|c|c|c|c|c|c|c|}
\hline \multirow[b]{4}{*}{ Independent variables } & \multicolumn{6}{|c|}{$\begin{array}{l}\text { Dependent variable: Choices in the distribution game } \\
(0=\text { allocation } \mathrm{A}, 1=\text { allocation } \mathrm{B}, 2=\text { allocation } \mathrm{C})\end{array}$} \\
\hline & \multicolumn{3}{|c|}{$\begin{array}{c}\text { New data } \\
\text { (panel E and F in Table 1) }\end{array}$} & \multicolumn{3}{|c|}{$\begin{array}{c}\text { All data } \\
\text { (panels B to F in Table 1) }\end{array}$} \\
\hline & (1) & (2) & (3) & (4) & (5) & (6) \\
\hline & Ey & $\mathrm{P}$ & Ey\&P & Ey & $\mathrm{P}$ & Ey\&P \\
\hline $\begin{array}{l}\text { Dummy for economist } \\
(1=\text { economist })\end{array}$ & $\begin{array}{l}-0.159 * * \\
(0.070)\end{array}$ & $\begin{array}{l}-0.207 * * * \\
(0.069)\end{array}$ & $\begin{array}{l}-0.183 * * * \\
(0.060)\end{array}$ & $\begin{array}{l}-0.258^{* * * *} \\
(0.043)\end{array}$ & $\begin{array}{l}-0.242 * * * \\
(0.043)\end{array}$ & $\begin{array}{l}-0.250 * * * \\
(0.037)\end{array}$ \\
\hline $\begin{array}{l}\text { Gender dummy } \\
\quad(1=\text { women })\end{array}$ & $\begin{array}{c}0.067 \\
(0.066)\end{array}$ & $\begin{array}{c}0.125^{*} \\
(0.066)\end{array}$ & $\begin{array}{c}0.095^{*} \\
(0.058)\end{array}$ & $\begin{array}{c}0.091 * \\
(0.048)\end{array}$ & $\begin{array}{l}0.086^{*} \\
(0.045)\end{array}$ & $\begin{array}{l}0.088^{* *} \\
(0.039)\end{array}$ \\
\hline $\begin{array}{l}\text { Political attitude } \\
\quad(0=\text { left, } 10=\text { right })\end{array}$ & $\begin{array}{c}-0.015 \\
(0.017)\end{array}$ & $\begin{array}{c}-0.003 \\
(0.017)\end{array}$ & $\begin{array}{c}-0.009 \\
(0.015)\end{array}$ & & & \\
\hline Age & $\begin{array}{c}-0.002 \\
(0.006)\end{array}$ & $\begin{array}{c}-0.002 \\
(0.006)\end{array}$ & $\begin{array}{c}-0.002 \\
(0.006)\end{array}$ & & & \\
\hline $\begin{array}{l}\text { Dummy for membership } \\
\text { in organizations }\end{array}$ & $\begin{array}{c}0.073 \\
(0.068)\end{array}$ & $\begin{array}{l}0.105 \\
(0.069)\end{array}$ & $\begin{array}{c}0.089 \\
(0.059)\end{array}$ & & & \\
\hline Dummy for Ey-treatment & & & $\begin{array}{c}-0.034 \\
(0.034)\end{array}$ & & & $\begin{array}{r}-0.040 \\
(0.025)\end{array}$ \\
\hline $\operatorname{Pr}(\mathrm{C})$ if a noneconomist & 0.482 & 0.521 & 0.501 & 0.513 & 0.530 & 0.521 \\
\hline Number of observations & 216 & 216 & 432 & 407 & 443 & 850 \\
\hline Cluster per subjects & no & no & yes & no & no & yes \\
\hline Prob $>$ chi 2 & 0.103 & 0.008 & 0.006 & 0.000 & 0.000 & 0.000 \\
\hline Pseudo $R^{2}$ & 0.021 & 0.036 & 0.028 & 0.047 & 0.039 & 0.044 \\
\hline
\end{tabular}

Notes: The table reports the marginal effects of the different variables on choosing the egalitarian allocation C. Numbers in parentheses denote the standard error of the marginal effects. The marginal effects are evaluated at the point where the dummy for economists is set at zero. The estimated baseline probability of choosing allocation $\mathrm{C}$ for noneconomists is given in the row " $\operatorname{Pr}(\mathrm{C})$ if a noneconomist."

* Indicates the coefficient is statistically different from zero above the 0.1 significance level.

** Indicates the coefficient is statistically different from zero above the 0.05 significance level.

*** Indicates the coefficient is statistically different from zero above the 0.01 significance level.

collected information about their political attitudes and how they voted in the last general election. We also collected information about their age, gender, and their membership in organizations (such as sports clubs or local charities). We recruited 58 third-semester students of economics or business administration from the University of Zurich and 100 third-semester students from other disciplines (law and medicine) and an additional 62 noneconomists from outside the university. These last subjects were nonmanagement employees of banks and other financial institutions. They had no college education, but all of them had completed an apprenticeship for their current job.

The subjects' political preferences were elicited in two ways. First, subjects ranked themselves on a scale from 0 to 10 , where 0 indicates the most extreme left-wing position and 10 indicates the most extreme right-wing position. This self-report measure of political attitudes is now widely used in representative surveys in
Switzerland. In addition, we asked subjects how they voted in the last national election. Both economists and noneconomists participated in these elections at a rate of approximately 70 percent. For these subjects, we computed a Spearman rank correlation between their selfreported political attitudes on the $0-10$ scale and their votes for left, center, and right parties. ${ }^{5}$ This correlation is $0.78(p<0.001)$, indicating that subjects' ranking on the left-right scale and their actual voting behavior are consistent.

The results of our new experiments are displayed in panels $\mathrm{E}$ and $\mathrm{F}$ of Table 1 and in Table 2. We first tested for differences between

\footnotetext{
${ }^{5}$ In these calculations, we treat the social democrats and the green party as left-wing parties, the liberal party (FDP), the Christian democrats (CVP), and the Evangelical people's party (EVP) as center parties, and the Swiss people's party (SVP) as a right-wing party. This classification is also used by political scientists.
} 
students from noneconomic disciplines and employees. It turns out that the behavior of these two groups is very similar, which is confirmed by statistical tests $(p=0.775$ in the Ey treatment, $p=0.739$ in the $\mathrm{P}$ treatment, Fisher exact test). Therefore, we pooled their data in panel $\mathrm{F}$ of Table 1. The table shows that both in treatment Ey and P, 53.5 percent of the economists prefer the efficient allocation A, whereas only 31 percent preferred the egalitarian allocation $\mathrm{C}$ (see panel E of the table). This pattern is reversed, however, among the noneconomists (panel $\mathrm{F}$ of Table 1). A majority of noneconomists (51.9 percent) prefers the most egalitarian allocation $\mathrm{C}$ and only 32.7 percent choose the efficient allocation A in treatment P. Similarly, a relative majority of the noneconomists (48.1 percent) prefers allocation $\mathrm{C}$ in treatment Ey and only 37.7 percent choose the efficient allocation A.

The differences between economists and noneconomists in self-reported political attitudes are small. On average, economists score 5.28 on the left-right scale, whereas the noneconomists are somewhat more left wing and score 4.95. This difference is statistically insignificant ( $p=0.41$, Mann Whitney test). There is, however, strong individual variation in both groups. It is therefore interesting to examine whether individual differences in political attitude can explain the individual variation in social preferences across subjects.

In Table 2, we report the marginal effects of ordered probit regressions where the choice of the most unequal allocation $\mathrm{A}$ is represented with 0 , allocation $\mathrm{B}$ with 1 , and the egalitarian allocation $\mathrm{C}$ with 2 . As explanatory variables, we included a dummy variable for economists ( 1 for economist), a gender dummy (1 for women), the political attitude on the left-right scale, age, and a dummy for whether the subject is a member in an organization or club. Regression (1) is based on data from the Ey treatment and regression (2) uses the data from the P treatment. We pool the data from both treatments in regression (3) and control for the potential dependence of subjects' decisions across treatments by clustering on subjects. We also control for a treatment effect in regression (3) by including a dummy for the Ey treatment.

The most important fact stemming from the first three regressions reported in Table 2 is that the marginal effect for the economists' dummy is negative and highly significant, even after controlling for political attitudes. In fact, while political attitude has virtually no effect on social preferences, regression (3) shows economists have an 18-percentage-point lower probability of choosing the egalitarian allocation C. Age, membership in organizations, and the Eydummy have no significant effects. The gender variable is weakly significant, however, and indicates that women are somewhat more egalitarian. If we average over both treatments (i.e., take regression 3), women are roughly 10 percent more likely to choose the egalitarian allocation $\mathrm{C}$.

We pooled all data from our experiments in regressions 4 to 6 to estimate the overall impact of the economists' dummy and a gender dummy on social preferences. ${ }^{6}$ The results of these regressions indicate that economists are 25 percentage points less likely to choose the egalitarian allocation $\mathrm{C}$, while women are more likely to choose $\mathrm{C}$ by 9 percentage points. Note, also, that if we pool the data from both treatments (regression 6) the gender dummy is significant at the 5-percent level.

\section{Conclusions}

Our experiments indicate that there is a strong subject pool effect in the simple distribution games of Engelmann and Strobel (2004). While a majority of economists prefer efficiency over equity, various groups of noneconomists, ranging from students of various other disciplines to low-level employees of banks and financial institutions, show the opposite pattern. On average, more than 50 percent of the noneconomists prefer the most egalitarian (and least efficient) distribution, while the probability of an economist choosing this allocation is 25 percentage points lower. Thus, we conclude that preferences for equity are of major importance in simple distribution experiments, even though there is a significant minority of subjects who seem to be concerned about efficiency. We have also shown that subjects' political preferences do not affect their social preferences for effi-

\footnotetext{
${ }^{6}$ We took all data reported in panels B to $\mathrm{F}$ in Table 1. Since we do not have values for age, political attitude, and membership in organizations in the experiments reported in panels $\mathrm{B}$ to $\mathrm{D}$, we cannot use these variables in the regressions 4 to 6 .
} 
ciency and equity. Subjects with a right-wing political attitude are as likely to choose the egalitarian allocation as left-wing subjects. Women, however, favor the egalitarian allocation more often than men do.

The relative importance of the different motivational forces seems to differ not only across subject pools but also across games. The E\&S experiments all involve dictator games without strategic interaction. Efficiency concerns are an important motivational force for a significant fraction of the subjects in these nonstrategic distribution games, but they seem to be far less important in strategic games such as bargaining, trust, or public good games. The ultimatum game is a striking case in point. Efficiency requires that the responder accept any positive offer. There is a huge amount of experimental evidence, however, showing that low offers are frequently rejected. Inequity aversion does a much better job of predicting behavior in these latter games, and it is consistent with the choices of a large fraction of the subjects in the E\&S distribution games. A better understanding of the functioning of different motivational forces in different environments is an important question for future research.

\section{REFERENCES}

Bolton, Gary E, and Axel Ockenfels. 2000. "ERC: A Theory of Equity, Reciprocity, and Competition." American Economic Review, 90(1): 166-93.

-Engelmann, Dirk, and Martin Strobel. 2004. "Inequality Aversion, Efficiency, and Maximin Preferences in Simple Distribution Experiments." American Economic Review, 94(4): 857-69.

-Fehr, Ernst, and Klaus M. Schmidt. 1999. "A Theory of Fairness, Competition, and Cooperation." Quarterly Journal of Economics, 114(3): 817-68. 